\title{
Contraception Provision in the Emergency Department: Are We Ready to Overcome the Obstacles?
}

\author{
Kayleigh Fischer, MD ${ }^{1}$ and Lauren S. Chernick, MD, $\mathrm{MSc}^{2}$
}

D ESPITE RECENT DECLINES in birth rates, adolescent females aged 15-19 years in the United States have one of the highest pregnancy rates among industrialized nations, with the majority of these pregnancies unintended. ${ }^{1}$ Adolescent unintended pregnancy has negative medical, financial, social, and emotional consequences for the pregnant adolescent, the child, the medical field, and society as a whole. $^{2,3}$ Adolescent mothers have increased high school dropout rates, with only $50 \%$ achieving high school diplomas by 22 years, leading to lower lifetime income potential and perpetuating socioeconomic disadvantages. ${ }^{4-6}$ The children of adolescent parents have higher risk of preterm birth, higher risk of health issues, lower school achievements, higher high school dropout rates, and higher likelihood of incarceration. ${ }^{7,8}$ Strategies are needed to decrease unintended teen pregnancy in novel places caring for high-risk teens.

The reduction of adolescent pregnancy remains a top priority of both the Center for Disease Control and Prevention and U.S. Department of Health and Human Services. ${ }^{6,9}$ They, along with multiple national academies, including The American Academy of Pediatrics and the American College of Obstetrics and Gynecology, have recognized the need for increased contraceptive care, which is the mainstay of pregnancy prevention. ${ }^{10-12}$ Medical providers are encouraged to offer contraception to all adolescents and reduce barriers to allow increased access to effective hormonal contraception. In addition, studies involving choice of hormonal contraception reveal that long-acting reversible contraceptive (LARC) methods such as the implant or intrauterine device, which are highly effective and easy to use, are a preferred method of contraception for women aged 14-45 years. ${ }^{13}$ These options should be explored with teens of all ages.

Our location where adolescent do seek medical care is in the emergency department (ED). More than 18 million adolescents use EDs every year with many being underinsured and having no primary care physician. ${ }^{14,15}$ Previous studies have demonstrated that adolescent females who use the ED participate in high-risk behaviors, in particularly risky sexual behaviors. ${ }^{16-18}$ Effective birth control use is infrequent, with single center studies showing up to one in five adolescent females expected to become pregnant in the subsequent year. ${ }^{17}$ Condom use is inconsistent, increasing the risk of sexually transmitted infections. ${ }^{19}$ Furthermore, in a national study, sex without contraceptives among teens aged 13-17 years was associated with other high-risk behaviors, such as binge drinking, depression, and conduct disorder. ${ }^{20}$ Given the number of high-risk adolescents seen in pediatric EDs, it forces us to wonder if the ED should be a point of access to hormonal contraception.

In this issue of The Journal of Women's Health, Gutman et al. explore the reproductive health practices of the adolescent population in the pediatric ED and their desire for contraceptive counseling and initiation in this setting. ${ }^{21}$ They surveyed a convenient sample of 381 females aged 16-21 years in one urban pediatric ED. The authors found that $39 \%$ of participants were using contraception, with more than half $(57.2 \%)$ satisfied with it. Two thirds were interested in learning more about hormonal contraception with one-third $(37.5 \%)$ interested in a LARC method. More than one quarter $(28 \%)$ had a history of a prior pregnancy.

The results of this study are consistent with previously published literature that the adolescent population in the pediatric ED have inadequate rates of contraception use but are interested in learning and initiating new methods. Many adolescent females who present to the pediatric ED are interested in initiation of contraception during their ED visit, particularly a LARC method. ${ }^{17,22,23}$ Notably, this study adds to the literature in that it highlights how many of those females using contraceptives are not satisfied with it. One reason for this might be that Gutman's population was older than those populations in other studies, with a mean age of 19 years instead of $16^{22,23}$ However, given that dissatisfaction with contraception can lead to discontinuation, this further emphasizes the risk of pregnancy among the ED female population.

The gap in care for this high-risk population exposes a potentially novel access point for initiating contraception, which in turn could lower rates of adolescent unintended pregnancy. However, should EDs be offering contraceptive care? First, provider comfort with discussing contraceptive options varies widely; this threatens the standardization of these practices. For example, although the placement of a LARC method such as an implant is quick, which may make it an ideal method for the ED, LARC methods require training for placement and a maintenance of that training. Second, billing and insurance is a major hurdle to the provision of contraception in the ED, especially LARC methods, as many require preauthorization. Third, both parental and provider

\footnotetext{
${ }^{1}$ Department of Pediatrics, Washington University in Saint Louis School of Medicine, Saint Louis, Missouri.

${ }^{2}$ Department of Emergency Medicine, Columbia University Medical Center, New York, New York.
} 
acceptance of offering contraception in the ED is an area that needs further exploration, as political, social, and ethical barriers may exist. Fifth, there is currently scant literature on the implementation process of contraceptive screening and provision or on the feasibility of offering LARC methods in the ED setting other than case studies. ${ }^{24,25}$

Yet, despite these barriers, the benefits to providing contraceptives are undeniable. Preventive care already occurs in the ED setting, with certain pediatric EDs implementing other public health, including screening for suicide and domestic violence. Medical directors are receptive to pregnancy prevention interventions. ${ }^{26}$ If we can design novel ways to weave contraceptive provision in to the ED workflow, such as using technology or outside assistance such as health educators, we may be closer to finding the middle ground in which our female patients are receiving the evidence-based patient-centered reproductive counseling they not only need but also deserve.

\section{References}

1. Mosher WD, Jones J, Abma JC. Intended and unintended births in the United States: 1982-2010. Natl Health Stat Report 2012:1-28.

2. United Nations Population Fund. Adolescent pregnancy: A review of the evidence. 2013. Available at: www.unfpa.org/ publications/adolescent-pregnancy Accessed December 1, 2016.

3. Romero L, Pazol K, Warner L, et al. Reduced disparities in birth rates among teens aged 15-19 years-United States, 2006-2007 and 2013-2014. MMWR Morb Mortal Wkly Rep 2016;65:409-414.

4. Oringanje C, Meremikwu MM, Eko H, Esu E, Meremikwu A, Ehiri JE. Interventions for preventing unintended pregnancies among adolescents. Cochrane Database Syst Rev 2016;2:CD005215.

5. Rich-Edwards J. Teen pregnancy is not a public health crisis in the United States. It is time we made it one. Int J Epidemiol 2002;31:555-556.

6. Centers for Disease Control and Prevention. Reproductive Health: Teen Pregnancy. Available at: https://www.cdc.gov/ teenpregnancy/about/index.htm Accessed September 1, 2016.

7. Elfenbein DS, Felice ME. Adolescent pregnancy. Pediatr Clin North Am 2003;50:781-800, viii.

8. Koniak-Griffin D, Turner-Pluta C. Health risks and psychosocial outcomes of early childbearing: A review of the literature. J Perinat Neonat Nurs 2001;15:1-17.

9. Center for Disease Control and Prevention. Contraception: How effective are birth control methods? 2016. Available at: https://www.cdc.gov/reproductivehealth/contraception Accessed January 1, 2017.

10. American College of Obstetricians and Gynecologists. Guidelines for adolescent health care. 2011. Available at: www.acog.org/About-ACOG/ACOG-Departments/AdolescentHealth-Care Accessed December 1, 2016.

11. American Congress of Obstetricians and Gynecologists. Statement on Teen Pregnancy and Contraception. 2015. Available at: www.acog.org/About-ACOG/News-Room/ Statements/2015/ACOG-Statement-on-Teen-Pregnancyand-Contraception Accessed December 1, 2016.

12. Committee on Adolescence. Contraception for adolescents. Pediatrics 2014;134:e1244-e1256.
13. Birgisson NE, Zhao Q, Secura GM, Madden T, Peipert JF. Preventing unintended pregnancy: The Contraceptive CHOICE Project in Review. J Womens Health (Larchmt) 2015;24:349-353.

14. Schappert SM, Rechtsteiner EA. Ambulatory medical care utilization estimates for 2006. Natl Health Stat Report 2008:1-29.

15. Wilson KM, Klein JD. Adolescents who use the emergency department as their usual source of care. Arch Pediatr Adolesc Med 2000;154:361-365.

16. Ahmad FA, Jeffe DB, Plax K, et al. Characteristics of youth agreeing to electronic sexually transmitted infection risk assessment in the emergency department. Emerg Med J 2018;35:46-51.

17. Chernick L, Kharbanda EO, Santelli J, Dayan P. Identifying adolescent females at high risk of pregnancy in a pediatric emergency department. J Adolesc Health 2012;51: 171-178.

18. Chernick LS, Chun TH, Richards R, et al. Sex without contraceptives in a Multicenter Study of Adolescent Emergency Department Patients. Acad Emerg Med 2019. DOI:10.1111/acem.13867

19. Walton MA, Resko S, Whiteside L, Chermack ST, Zimmerman M, Cunningham RM. Sexual risk behaviors among teens at an urban emergency department: Relationship with violent behaviors and substance use. J Adolesc Health 2011;48:303-305.

20. King CA, Brent D, Grupp-Phelan J, et al. Five profiles of adolescents at elevated risk for suicide attempts: Differences in mental health service use. J Am Acad Child Adolesc Psychiatry 2019. pii: S0890-8567(19)32222-1.

21. Gutman CK, Dorfman D, Meese H, et al. Identifying a golden opportunity: Adolescent interest in contraceptive initiation in a pediatric emergency department. J Women's Health 2020;29:620-624.

22. Hoehn EF, Hoefgen H, Chernick LS, et al. A pediatric emergency department intervention to increase contraception initiation among adolescents. Acad Emerg Med 2019; 26:761-769.

23. Miller MK, Randell KA, Barral R, Sherman AK, Miller E. Factors associated with Interest in same-day contraception initiation among females in the pediatric emergency department. J Adolesc Health 2016;58:154-159.

24. Potter J, Koyama A, Coles MS. Addressing the challenges of clinician training for long-acting reversible contraception. JAMA Pediatr 2015;169:103-104.

25. Koyama A, Dorfman DH, Forcier MM. Long-acting reversible contraception in the pediatric emergency department: Clinical implications and common challenges. Pediatr Emerg Care 2015;31:286-292; quiz 293-295.

26. Ahmad FA, Jeffe DB, Carpenter CR, et al. Emergency department directors are willing to expand reproductive health services for adolescents. J Pediatr Adolesc Gynecol 2019;32:170-174.

Address correspondence to: Lauren S. Chernick, MD, MSc Department of Emergency Medicine Columbia University Medical Center 3959 Broadway, CHN 1-116 New York, NY 10032

E-mail:1c2243@columbia.edu 